\title{
Peer Reviewers of Academic Journals: Who Is Responsible for Our Professional Literature
}

\section{Mary Francis}

\begin{abstract}
Scholarly journals provide a record of the research, issues, and concerns of a field. Authors have their names associated with their individual articles, while editors are connected with a publication. However, there is another group of individuals who are often left out of the record, although their contributions are just as critical in the formation of scholarly journals. This article will take a look at this group of peer reviewers, to provide demographic data as well as understanding for the reasons individuals take on the duty of peer reviewer.
\end{abstract}

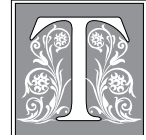

he process of academic peer review began more than 300 years ago with Philosophical Transactions of the Royal Society of London. In the ensuing years, peer review has become fully engrained into the lives of many professionals, with the peer-reviewed journal serving as a critical method of disseminating research findings. "A peer-reviewed journal is one that has a portion of submitted manuscripts evaluated by someone other than the editor of the journal." 1 The process may vary by discipline or even by journal. However, the goal of peer review is to ensure the quality of material published within the journal. In a process that is open to variety, the basic process involves these steps: an author submits an article, the editor then distributes the article for comments to reviewer/s, the reviewers provide the editor with comments and opinion on the article, and the editor then makes a publication decision using his and the reviewers' comments.

Peer reviewers are a critical component of the scholarly publishing system. The responsibilities of a peer reviewer include: providing judgment on the quality of the submitted work, being familiar within the subject to provide opinion as to the innovation or importance of the submitted work, recommending changes to improve the quality of the submitted work, maintaining a standard of quality for the journal and research within the field, and fulfilling their duties in an ethical manner. Benefits of peer reviewing include: keeping up to date on research in the field, credit toward promotion or tenure, experience to improve personal research and writing skills, and support of their field. The monetary benefits of peer reviewing are often limited, with few journals offering payment for reviews.

Mary Francis is Reference Instruction Librarian in the Karl E. Mundt Library at Dakota State University; e-mail:mary.francis@dsu.edu. (C) 2013 Mary Francis, Attribution-NonCommercial (http://creativecommons. org/licenses/by-nc/3.0/) CC BY-NC 
The future of scholarly publishing is complex and beyond the scope of this paper. Open access, electronic publishing, and institutional repositories all must be considered. There have been multiple calls to change the present scholarly publishing model. ${ }^{2}$ Amid the changes there remains the fact that "peer review must remain in any new model. In the era of ever increasing material, a certification system is required more urgently than ever." ${ }^{3}$ Review by others within the field is critical to maintain a rigorous, living profession. The evaluation that occurs through review offers a method to determine the quality of published material that would otherwise be lacking. The process of peer review may change, yet the evaluation process will persist. Suggestions for a revised review process have been made by several individuals including Vitez Tracz who has created the website Faculty of 1,000 as a location for open publishing and rating of articles. ${ }^{4}$ Other journals are experimenting with an open review process with articles available for online comments. Nature and Shakespeare Quarterly have both tested this model, Nature unsuccessfully and Shakespeare Quarterly successfully. ${ }^{5}$ Fitzpatrick offers a look at the open peer review and how it could change authority. ${ }^{6}$

The peer-review process is not immune to controversy, however. Common complaints against the process include: bias on the part of the editor or reviewer, reviewers taking ideas for their own use, reviewers stalling the publication for personal gain, unknowledgeable reviewers, or mean or unhelpful personal attacks by reviewers. Debate also occurs between advocates of blind, double-blind, and open- review process. One example of this discussion can be seen in the pro/ con articles discussing the issue within BMJ. ${ }^{7}$ However, even amid the problems within the system, the overall process still maintains the support of most within assorted professional disciplines. As noted by Chanson, "a research project is only completed when it has been published and shared with the community." 8

\section{Literature Review}

There have been a number of studies looking at the demographics of authors of library and information science journals. ${ }^{9}$ These studies have offered a look at who is responsible for providing a public discussion of the library field. There is another group involved in the process who also play a major role in developing our record in published form that have been overlooked in previous studies: the peer reviewer. These anonymous individuals play a major role in determining what types of articles will be published. Given the essential role of peer reviewers in scholarly publishing, it is important that we know these individuals.

Much of the literature on peer review is editorial rather than research based, both from editors describing the process at particular journals ${ }^{10}$ to others describing the merits or lack thereof of the peer-review process. ${ }^{11}$ In her 2001 work, Weller offers a book-length treatment looking at the assorted articles and research that have looked at peer review. Her book breaks up the research into several broad categories providing analysis of the research done and suggestions for future research. These studies cover every aspect of the peer-review process from a variety of disciplines. $^{12}$

Studies from the field of library science are scarce, with Glogoff offering the only study focusing on the characteristics of peer reviewers. ${ }^{13}$ His survey of peer reviewers looked at both review practices and demographics. His demographic data included academic degree, type of library employed, whether peer review would help promotion and tenure, connection with national library associations, whether reviewers were reviewing for more than one journal, details on what journals the reviewers published in, and how many journals they regularly read. From his survey, he discovered that 73 percent of peer reviewers worked at academic libraries or schools of library and information science. His theory that referees are prominent in their field was 
supported by the discovery that 71 out of 98 reviewers belonged to national associations.

A good peer reviewer has the following qualities as offered by Salasche within Weller: ${ }^{14}$ expertise on the subject; not necessarily an "expert"; willing to take time to be thorough; willing to make the paper better; can make an informed, unbiased decision; and has no conflict of interest. Among the responsibilities of the peer reviewer, the ultimate goal is to work with authors and editors to publish high-quality articles. While there is often no formal training given to individuals when they become peer reviewers, editors can provide guidance. Articles providing insight and guidelines on the review process have been written by Alexander, Fischer, and Griffin-Sobel. ${ }^{15}$

Beyond serving as a gatekeeper for publishing quality papers, "studies have shown that review does improve manuscripts, but the degree of improvement is hard to pinpoint." 16 Hentschel and Pokorny conducted a five-year study looking at submitted papers finding an "improvement from the first to last submission of a paper to the journal." ${ }^{17} \mathrm{Au}-$ thors have also noted that working with the review process has resulted in better papers. One study showed 90 percent of respondents agreeing with the statement that "peer review improves the quality of the published paper." ${ }^{\prime 18}$

\section{Methods}

The journals chosen for the survey were listed among the top five most prestigious by eight or more LIS Deans and ARL Directors from the Nisonger and Davis article. ${ }^{19}$ Also included are additional titles suggested by eight or more ARL Directors or LIS Deans to add to the survey titles. Selected journals were limited to peerreviewed titles that use an open call for articles. Perception of importance rather than impact factor is used as the choice of journals due to the problems inherent to the assignment of impact factor. The eleven journals surveyed were: College $\mathcal{E}$
Research Libraries, Information Processing $\mathcal{E}$ Management, Journal of Academic Librarianship, Journal of Documentation, Journal of the American Society for Info Science and Technology, Library Quarterly, Library Resources E Technical Services, Library $\mathcal{E}$ Information Science Research, Libres, portal: Libraries and the Academy, and Reference \& User Services Quarterly.

The editors of each journal were identified and contacted via e-mail with a request to complete an online survey discussing their reviewers. They were also asked to forward a request to their reviewers to complete a separate survey collecting demographic and opinion information. This was to ensure that the peer reviewers would remain anonymous. No identifying data were collected within either survey. One reminder e-mail was sent to the editors.

\section{Findings}

There were six responses from the editor surveys, for a 54 percent response rate. The first question asked how many peer reviewers were used by the journal. Responses ranged from 15 to 80 reviewers, with two journals having 15 reviewers and the others having 30,50 , and 80 with one providing no response. The next question asked whether there was a length of service for peer reviewers. A total of 66 percent of the journals had no set limit on serving. One had a five-year limit and the other had two-year terms with the option of a second term. Question 3 addressed monetary compensation for reviewers. Again, 66 percent offered no compensation with reviewers serving as volunteers. The remaining 33 percent provided reviewers with a free journal subscription. Question 4 asked how the editors gain new reviewers. The choices included: open call, ask specific individuals, recommendations, and an option for additional methods. More than one choice could be selected. More than three quarters (83\%) noted they asked specific individuals. In describing how they choose which individual to ask, 


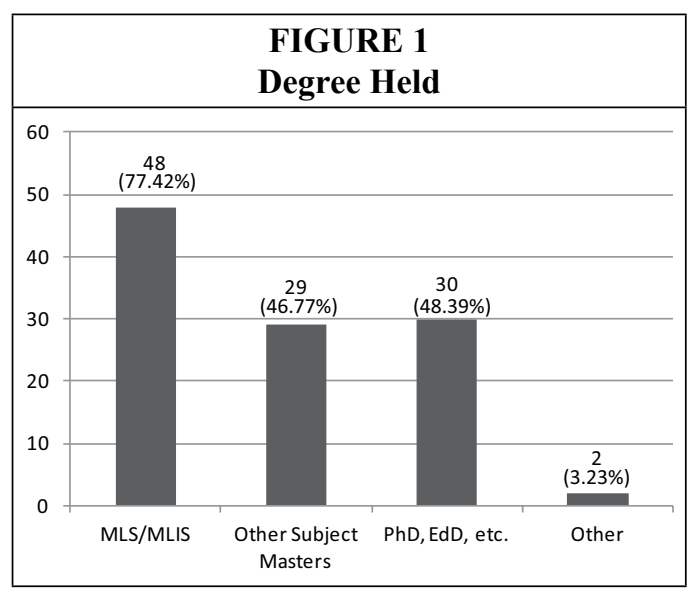

and 36 percent were male. More than three quarters $(77 \%)$ of the respondents held a MLS/MLIS degree. Nearly half (46\%) held a master's in another subject, while 48 percent held a $\mathrm{PhD}$, EdD, etc. Respondents were pretty evenly spread geographically, with the largest percentage of individuals from the Midwest at 25 percent. The Northeast had 20 percent. The Southeast and West both had 16 percent. The Southwest had 11 percent. Canada had 3 percent with 5 percent claiming other locations. Respondents had significant

many noted that they looked at authors who had published within the area as well as individuals who had experience in a particular area. One third (33\%) also noted that they take recommendations. These come from board members as well as colleagues. None of the editors used an open call to gain peer reviewers. The final question asked for any additional observations about who becomes a peer reviewer. Several respondents noted that the reviewers often have an active record of publication themselves. One respondent noted that "Whether a person is asked to review repeatedly is determined by the timeliness of once the reviewer accepts an invitation and by the quality of the review."

The peer reviewer survey was completed by 62 respondents. Due to the fact that an unknown number of reviewers were sent a link to the survey as a means to maintain confidentiality, it is not possible to know the response rate. The seventeen questions gathered data on demographics, scholarly activity, reasons for being a reviewer, opinion on signed reviews, and an option for additional comments. A list of the questions can be found in Appendix A.

The eight demographic questions revealed that 63 percent of the respondents were female experience working in library information science, with 41 percent noting 31 or more years of experience. Nearly one third (32\%) fell within the range of 16-30 years of experience. Almost one quarter (22\%) had 6-15 years of experience. Only 3 percent had $0-5$ years of experience in the field. The majority of the respondents (63\%) worked at an academic library, 16 percent worked within a School of Library and Information Science, and 9 percent either were retired or chose other. No one noted they worked at a public, school, or special library. For those reporting their schools' Carnegie classification, 71 percent were from a doctorate-granting university. Another 17 percent were from a master's college or university. The rest were either from a baccalaureate college, associate's college, or special-focus institution.

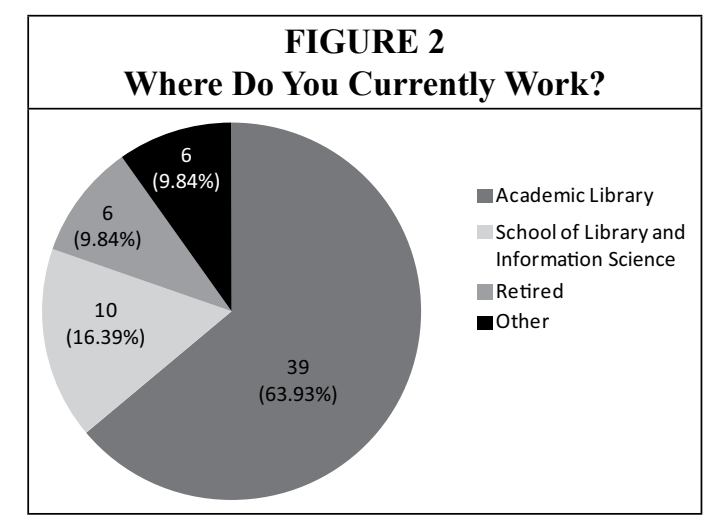




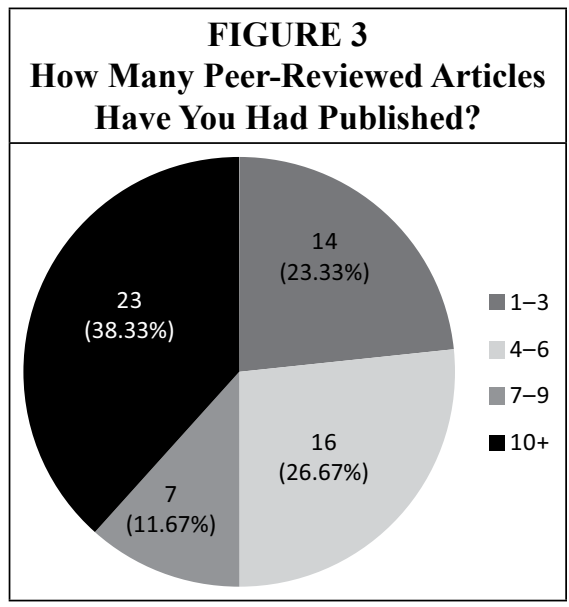

The next question dealt with faculty status. Just over two thirds (67\%) reported having faculty status, but 16 percent reported not having faculty status. The remaining 16 percent noted it was not applicable or other. In relation to being tenured or in a tenure track position, 61 percent of respondents noted they were in such a position, and 27 percent reported they were not. For the remaining 11 percent, it was not applicable.

The next five questions related to scholarly activity. When asked if they had ever been published in a peer-reviewed library or information science journal, 98 percent of the respondents said yes. Of those respondents, 38 percent had pub- lished 10 or more peer-reviewed articles, 11 percent had published 7-9 articles, 26 percent had published 4-6 articles, and 23 percent had published $1-3$ articles. Of the respondents, a little more than half (51\%) had only been a peer reviewer for $0-5$ years; 20 percent had been a reviewer for 6-10 years, 20 percent had reviewed between 11 and 30 years, while 6 percent had reviewed for 31 or more years. The respondents also tended to review for a small number of journals: 58 percent were currently reviewing only 1 journal, 20 percent were reviewing for 2 journals, 11 percent were reviewing for 3 journals, and 4 percent were reviewing either 4 or more journals currently. There was a greater variety when the respondents were asked how many journals they had reviewed for throughout their career: 38 percent had reviewed for 1 journal, 12 percent had reviewed for 2 journals, 24 percent had reviewed for 3 journals, 8 percent had reviewed for 4 journals, and 16 percent had reviewed for 5 or more journals.

When asked why they were peer reviewers, almost all respondents (96\%) noted it was a way to help the profession. Nearly three quarters $(70 \%)$ felt it was a way to keep up on library-related research, 12 percent reviewed for promotion requirements, while 6 percent reviewed for tenure requirements. Only

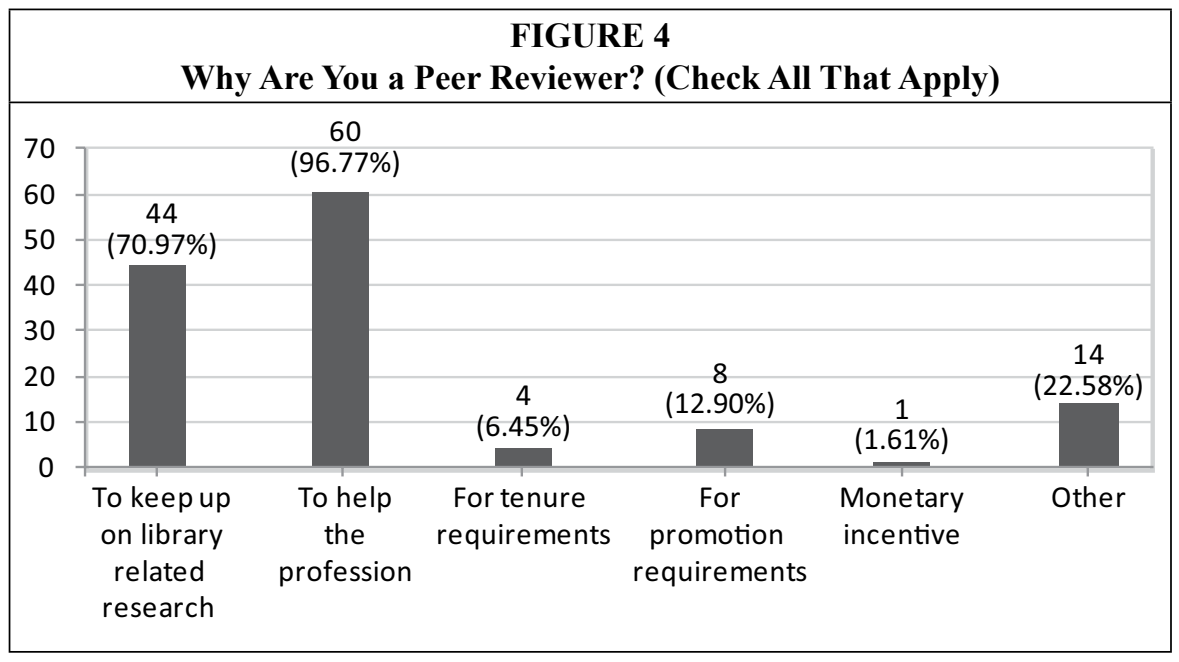


1 percent listed monetary incentive as a reason to be a peer reviewer, and 22 percent of respondents also noted other as a reason for being a peer reviewer. When asked to rank their reasons for being a peer reviewer, the majority listed helping the profession as their most important reason for being a peer reviewer.

The next question asked the reviewers their opinion on signed reviews. When asked whether having the author know you reviewed the article affected your decision to be a peer reviewer, 42 percent said no, they would still review the article; 40 percent said yes, they would not want to review the article.

\section{Discussion}

A surprising result from the editor survey was the fact that of the journals surveyed, none used an open call for reviewers. It is up to the editor to find individuals to review. In the additional comments, several editors noted that peer reviewers have an extensive publishing history; however, given the fact that many are chosen by an editor who found them through a review of authors, this is not unexpected.

In looking at the degrees held by the reviewers, it is interesting to see that only 77 percent hold an MLS/MLIS degree. Considering the fact that they are reviewing articles for some of the most highly ranked library and information science journals, one would expect that they would all hold degrees in the field. They were not lacking in educational attainment, however, as close to half noted they held other subject master's degrees, with another 48 percent holding a PhD, an EdD, or another doctorate.

The reviewers are well engrained in the field, as more than 50 percent of the respondents have worked in the field for more than 26 years. However, most of the respondents have not been reviewing for much of that time. With more than 50 percent of the respondents having reviewed for 5 or fewer years, it appears that reviewing may be a service that librarians are entering later in their careers. It may be possible that these individuals began reviewing after establishing their own publication careers. This would follow from the comments by the editors, who often look for established authors to ask to review. It also holds with the fact that 98 percent of the respondents had been published in peer -reviewed library and information science journals. Considering that 38 percent of these individuals had published 10 or more articles, it would appear that they are well established in the library literature.

Given the fact that the surveyed journals were chosen by LIS Deans and ARL Directors leading to an academic library slant, it is not surprising that more than 80 percent of the respondents worked either at an academic library or school of library and information science. An interesting fact is that, while 67 percent of the respondents had faculty status and 61 percent were tenured or on tenure track, only 6 percent listed tenure requirements as a reason that they were a reviewer and only 12 percent listed promotion requirements as a reason. To help the profession was by far the most important and most often noted reason to be a reviewer. Only 2 respondents did not list it as a reason to review.

The almost equal split in regard to signed reviews shows the split that occurs throughout all fields of scholarly publishing regarding the faults and benefits of the traditional double-blind review process. Under the question asking for additional comments about being a peer reviewer, there were 23 responses. Seven of those comments offered positive comments on the process of blind reviewing, noting that "signed reviews have the potential to introduce bias." One respondent noted, "as both a journal editor and peer reviewer, I believe that the double blind process is essential to maintaining the integrity of the review process."

Another theme that appeared within the open comment question related to the quality of the submitted work. Several comments noted the "poor quality" 
of submitted manuscripts. Noting that "it can sometimes be frustrating to peer review because for every acceptable manuscript there are 5 unacceptables." There were also a couple of comments wondering about the ability of reviewers to critically review some aspects of research such as quantitative statistics. One respondent noted "some of the top practitioner-oriented LIS journals have published papers that would have been rejected by a mid-level sociology or political science journal."

Another set of comments dealt with the theme of how reviewing has helped the reviewers with their own research, writing, and critical thinking skills. "I have benefited from wonderful feedback on my own research so can only hope my comments help others improve their work." The reviewers' comments note the importance of peer reviewing and consider it "worth the investment of time."

\section{Limitations}

This was a limited survey of eleven peerreviewed journals. The selected journals were listed by LIS Deans and ARL Directors, which gave an academic library slant to the choices. This study should be repeated to check for differences in journals focused toward public, school, or special libraries or journals that are not rated as prestigious. It would be interesting to see if the increasing numbers of journals, focusing on unique and more specialized aspects of librarianship, are reviewed by a different set of peer reviewers. It may be that more new librarians are serving as peer reviewers for these journals to gain experience, just as they may publish in these smaller journals before publishing in a more well-known journal. Future research within the subject of peer reviewers could look at the training or guidance that reviewers get when reviewing.

\section{Conclusion}

While the peer reviewers within this survey were often new to peer reviewing, they brought to the process years of experience in the field as well as active publication records. This was overwhelmingly done as a service to the profession as well as a chance to keep up with current research. Peer reviewers are a critical component of the literature of our field. As noted in a comment by one reviewer to the survey, "reviewers have the opportunity to shape the kind and content of our scholarly record, and their work represents a significant service contribution to the profession." Due to this fact, it is important that we look at these individuals to maintain a record of who they are and why they offer their time, energy, and expertise to an often unacknowledged service for the field. 


\section{APPENDIX A}

\section{Editor Survey}

1. How many peer reviewers do you have for your journal?

2. Does your journal have a length of service for peer reviewers? If so, how long do your peer reviewers serve?

3. How do you gain new peer reviewers?

a. Ask specific individuals

b. Recommendations

c. Open call

d. Other

4. You noted that you gain peer reviews through an open call. How do you sort through your open call volunteers?

5. You noted that you gain new peer reviewers by asking specific individuals. How do you determine which individuals you ask?

6. You noted that you gain new peer reviewers through recommendations. Who do you get your recommendations from?

7. Do you have any additional observations about who becomes a peer reviewer?

\section{Peer Reviewer Survey}

1. Sex
a. Male
b. Female

2. Degree Held
a. MLIS/MLS
b. Other subject masters
c. $\mathrm{PhD}, \mathrm{EdD}$, etc.
d. Other

3. Geographic Location
a. United States - Northeast
b. United States - Southeast
c. United States - Midwest
d. United States - West
e. United States - Southwest
f. Canada
g. Others

4. How long have you worked in the library/information science field?
a. $0-5$ years
b. 6-10 years
c. 11-15 years
d. 16-20 years
e. 21-25 years
f. 26-30 years
g. $31+$ years

5. Where do you currently work?
a. Academic Library
b. Public Library
c. School Library
d. Special Library
e. School of Library and Informa- tion Science
f. Retired
g. Other

6. What is your Carnegie Classification?
a. Doctorate-Granting University
b. Master's College and University
c. Baccalaureate College
d. Associates College
e. Special-Focus Institution

7. Do you have faculty status?
a. Yes
b. No
c. N.A.
d. Other

8. Are you tenured or in a tenure-track position?
a. Yes
b. No
c. N.A. 
9. Have you been published in peerreviewed library and information science journals?
a. Yes
b. No

10. How many peer-reviewed articles have you had published?
a. 1-3
b. $4-6$
c. 7-9
d. $10+$

11. How many years have you been a peer reviewer for a library-related journal?
a. $0-5$ years
b. 6-10 years
c. 11-15 years
d. 16-20 years
e. 21-25 years
f. 26-30 years
g. $31+$ years

12. How many journals are you currently a peer reviewer for?
a. 1
b. 2
c. 3
d. 4
e. $5+$

13. Throughout your career, for how many journals have you been a peer reviewer?
a. 1
b. 2
c. 3
d. 4
e. $5+$

14. Why are you a peer reviewer for library-related journals? Check all that apply.
a. To keep up on library-related research
b. To help the profession
c. For tenure requirements
d. For promotion requirements
e. Monetary incentive
f. Other

15. Rank the reasons you are a peer reviewer from the most important to the least important.

16. Considering signed reviews: Would having the author know you reviewed the article affect your decision to be a peer reviewer?
a. Yes, I would not want to review the article
b. No, I would still review the article
c. Other

17. Do you have any additional comments you would like to make about being a peer reviewer for a scholarly journal? 


\section{Notes}

1. Ann C. Weller, Editorial Peer Review: Its Strengths and Weaknesses (Medford, N.J.: American Society for Information Science and Technology, 2001).

2. Miriam A. Drake, "Scholarly Communication in Turmoil," Information Today 24, no. 2 (2007): 1, 18-19; Thomas H.P. Gould, "Scholar as E-Publisher: The Future Role of [Anonymous] Peer Review within Online Publishing," Journal of Scholarly Publishing 41, no. 4 (2010): 428-48; Tai-Yin Huang, "Peering into Peer Review," Physics Today 61, no. 12 (2008): 14; David Roman, "Scholarly Publishing Model Needs an Update," Communications of the ACM 51, no. 1 (2011): 16, 96; Danny Kingsley, "The Journal Is Dead, Long Live the Journal," On the Horizon 15, no. 4 (2007): 211-21; "Lift the Veil of Secrecy," New Scientist 206, no. 2764 (2010): 3; David B. Resnik, "A Troubled Tradition," American Scientist 99 (2011): 24-27.

3. Kingsley, "The Journal Is Dead," 215.

4. Colin Macilwain, "'Facebook of Science' Aims to Reshape Peer Review," Chronicle of Higher Education 57, no. 22 (2011): A6-A7.

5. Jennifer Howard, "Leading Humanities Journal Tries 'Open' Peer Review, and Likes It," Chronicle of Higher Education 56, no. 42 (2010): A11.

6. Kathleen Fitzpatrick, "Peer-to-Peer Review and the Future of Scholarly Authority," Social Epistemology 24, no. 3 (2010): 161-79.

7. Karim Khan and Trish Groves, "Is Open Peer Review the Fairest System?" BMJ: British Medical Journal 341, no. 7782 (2010): 1082-83.

8. Hubert Chanson, "Research Quality, Publications, and Impact in Civil Engineering into the 21st Century: Publish or Perish, Commercial Versus Open Access, Internet Versus Libraries?" Canadian Journal of Civil Engineering 34, (2007): 946-51.

9. Martha C. Adamson and Gloria J. Zamora, "Publishing in Library Science Journals: A Test of the Olsgaard Profile," College \& Research Libraries 42, no. 3 (1981): 235-41; Paula De Simone Watson, "Publication Activity among Academic Librarians," College \& Research Libraries 38, no. 5 (1977): 375-84; Paula D. Watson, "Production of Scholarly Articles by Academic Librarians and Library School Faculty," College \& Research Libraries 46, no. 4 (1985): 334-42; Stephen E. Wiberley Jr., Julie M. Hurd, and Ann C. Weller, "Publication Patterns of U.S. Academic Librarians from 1998 to 2002," College \& Research Libraries 67, no. 3 (2006): 205-16; John N. Olsgaard and Jane Kinch Olsgaard, "Authorship in Five Library Periodicals," College \& Research Libraries 41, no. 1 (1980): 49-53; Richard L. Hart, "Scholarly Publication by University Librarians: A Study at Penn State," College E Research Libraries 60, no. 5 (1999): 454-62; Michelle Penta and Pamela J. McKenzie, "The Big Gap Remains: Public Librarians as Authors in U.S. Journals, 1999-2003," Public Library Quarterly 24, no. 1 (2005): 33-46.

10. Ron Weber, "Retrospection: The MIS Quarterly's Review Process: 1995-2001," MIS Quarterly 26, no. 2 (2002): v-xi.

11. "Support for Peer Review," Nature Immunology 11, no. 12 (2010): 1063; Nick Rushby, "Peer Review," British Journal of Educational Technology 41, no. 5 (2010): 668-71.

12. Weller, Editorial Peer Review.

13. Stuart Glogoff, "Reviewing the Gatekeepers: A Survey of Referees of Library Journals," Journal of the American Society for Information Science 39, no 6 (1988): 400-07.

14. Weller, Editorial Peer Review, 154.

15. Greg R. Alexander, "A Guide to Reviewing Manuscripts," Maternal and Child Health Journal 9 , no. 1 (2005): 113-17; Charles Fischer, "A Value-Added Role for Reviewers in Enhancing the Quality of Published Research," Journal of Scholarly Publishing 42, no. 2 (2011): 226-37; Joyce P. Griffin-Sobel, “Tips for Reviewing Manuscripts," Clinical Journal of Oncology Nursing 8, no. 6 (2004): 653.

16. Weller, Editorial Peer Review, 171.

17. Uwe Hentschel and Dan Pokorny, "A Study of the Intersubject Reviewer Agreement and Manuscript Improvement during the Evaluation Process of Journal Submissions," Behavioral \& Social Sciences Librarian 27, no. 2 (2008): 92-103.

18. Mark Ware Consulting Ltd, "Peer Review in Scholarly Journals: Perspective of the Scholarly Community - An international Study," (2007), available online at www.publishingresearch.net/ documents/PeerReviewFullPRCReport-final.pdf [accessed 22 December 2011].

19. Thomas E. Nisonger and Charles H. Davis, "The Perception of Library and Information Science Journals by LIS Education Deans and ARL Library Directors: A Replication of the KohlDavis Study," College \& Research Libraries 66, no. 4 (2005): 341-77. 